\title{
Notes on the vocalizations of Pectoral Sparrow (Arremon taciturnus)
}

Peter Boesman

In the following we briefly analyze and compare voice of the three races of Pectoral Sparrow (Arremon taciturnus). We also try to quantify the extent of any vocal differences using the criteria proposed by Tobias et al. (2010), as a support for taxonomic review.

We have made use of sound recordings available on-line from Xeno Canto (XC).

Song typically starts with a few short introductory notes and is followed by 2-4 high-pitched hissing notes. A comparison of song of the three races, illustrated with sonograms:

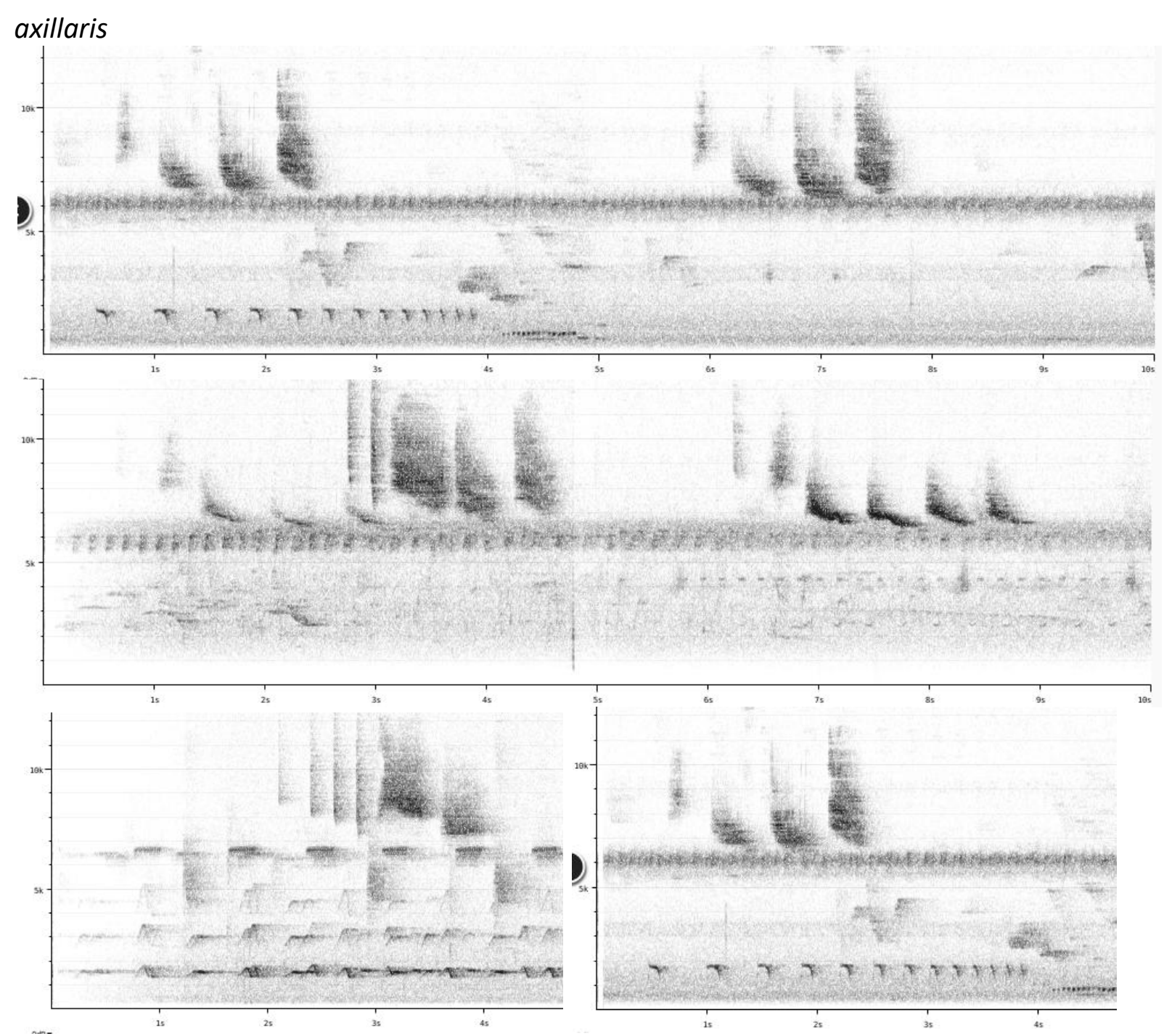




\section{HANDBOOK OF THE \\ BIRDSPF THE WORLD}

nominate

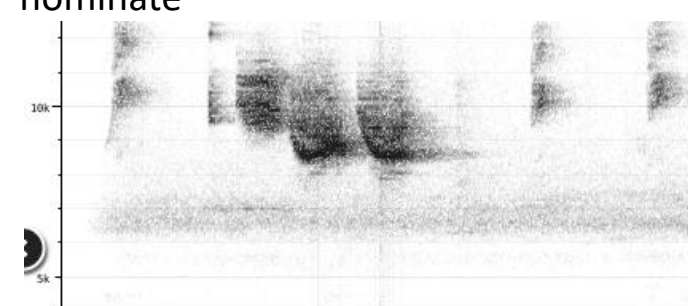

\section{ORNITHOLOGICAL NOTES}
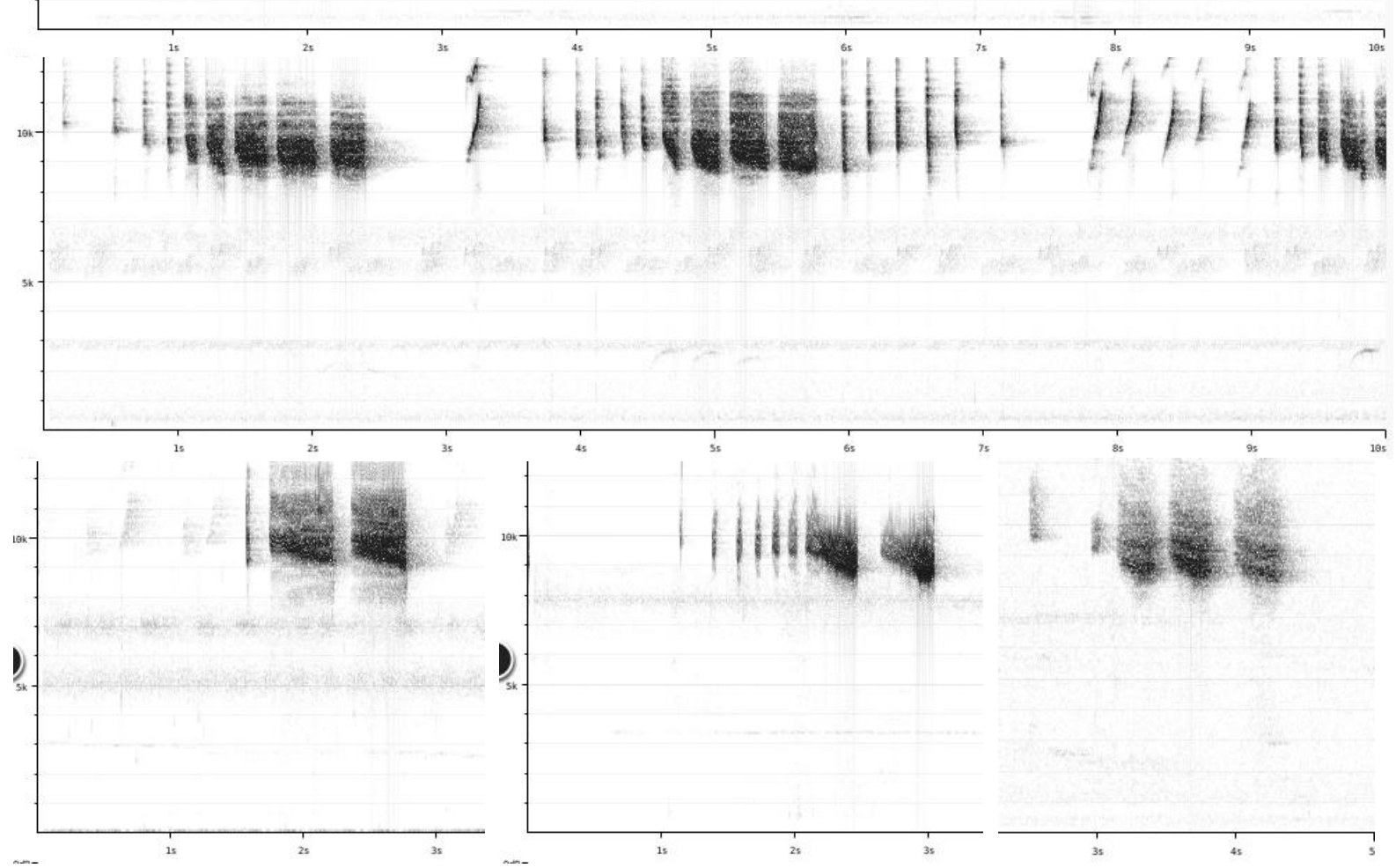

nigrirostris

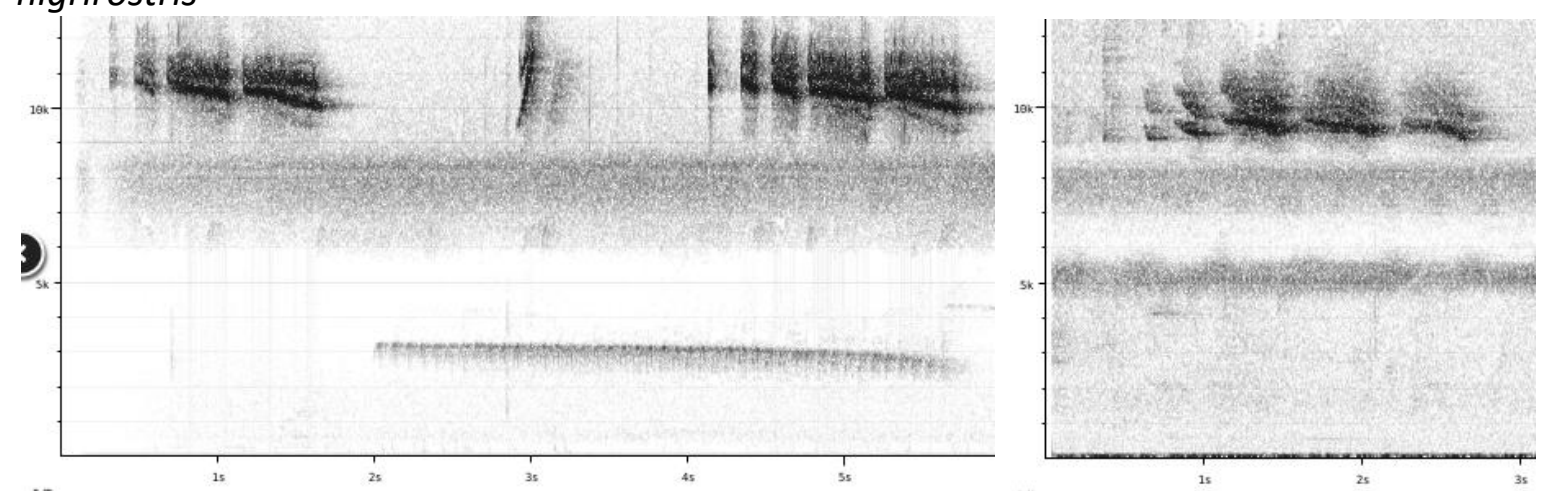



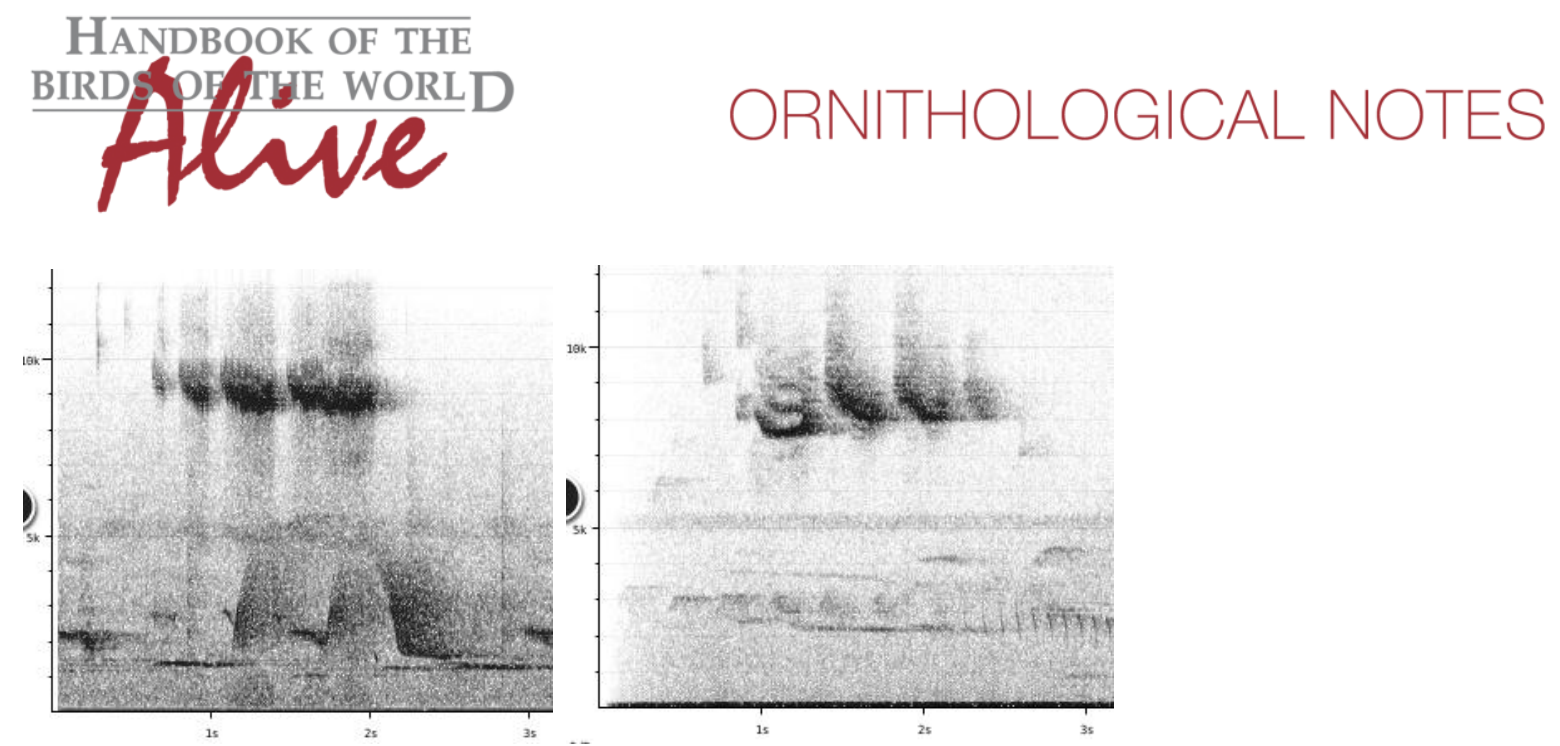

Song of all 3 races is structurally very similar. Race axillaris seems to reach lower frequencies, with hissing end notes typically going down to $7-7.5 \mathrm{kHz}$. Other races have end notes staying well above $8 \mathrm{kHz}$. Score 2 .

This vocal difference is thus rather minor, and much less outspoken than vocal difference with Half-collared Sparrow $A$. semitorquatus.

This note was finalized on 25th May 2016, using sound recordings available on-line at that moment. We would like to thank in particular the many sound recordists who placed their recordings for this species on XC.

\section{References}

Tobias, J.A., Seddon, N., Spottiswoode, C.N., Pilgrim, J.D., Fishpool, L.D.C. \& Collar, N.J. (2010). Quantitative criteria for species delimitation. Ibis 152(4): 724-746.

\section{Recommended citation}

Boesman, P. (2016). Notes on the vocalizations of Pectoral Sparrow (Arremon taciturnus). HBW Alive Ornithological Note 361. In: Handbook of the Birds of the World Alive. Lynx Edicions, Barcelona. (retrieved from http://www.hbw.com/node/1252905 on 1 November 2016). 